\title{
ALFABETIZAÇÃO CIENTÍFICA E TECNOLÓGICA COMO POSSIBILIDADE DE FORMAÇÃO DO CIDADÃO A PARTIR DE UMA ABORDAGEM DA EDUCAÇÃO EM SAÚDE
}

\author{
Sabrina Monteiroํㅡㄴ Luis Felipe Pissaia ${ }^{2}$, Mateus Lorenzon ${ }^{3}$, Eniz Conceição Oliveira ${ }^{4}$, \\ José Claudio Del Pino 5
}

Resumo: Este texto apresenta apontamentos sobre Alfabetização Científica e Tecnológica (ACT) como possibilidade de formação do cidadão e uma reflexão de uma vivência de uma professora dos anos iniciais de uma escola da rede estadual do Rio Grande do Sul, a partir de uma abordagem da educação em saúde. Nesse sentido, aborda-se diversas oportunidades de análise em relação à ACT, partindo dos pressupostos teóricos de Lorenzetti e Delizoicov (2001), Sasseron e Carvalho (2008 - 2011), Pérez Gómez (2015) e Frizon e Del Pino (2011) entre outros. Relata-se uma atividade desenvolvida a partir do assunto refrigerante, que foi apresentado na Mostra de Trabalhos da escola envolvida. Acredita-se que o ensino deve proporcionar a construção de uma cidadania para pensar, tomar decisões, propor alternativas e capaz de perceber aspectos positivos e negativos da ciência e tecnologia. Partindo dos apontamentos oriundos desse texto, percebe-se que existem diversas possibilidades de análise em relação à ACT na formação do cidadão, sendo a saúde uma delas.

Palavras-chave: Alfabetização Científica e Tecnológica. Formação do cidadão. Escola. Educação e Saúde.

1 Professora. Mestrando em Ensino. Universidade do Vale do Taquari UNIVATES. E-mail: sabrinamonteiro1991@gmail.com

2 Enfermeiro. Mestrando em Ensino. Universidade do Vale do Taquari UNIVATES. E-mail: 1pissaia@ universo.univates.br

3 Professor. Mestrando em Ensino. Universidade do Vale do Taquari UNIVATES. E-mail: mateusmlorenzon@gmail.com

4 Doutora em Química Ambiental. Universidade do Vale do Taquari UNIVATES. E-mail: eniz@ univates.br

5 Doutor em Engenharia - Química de Biomassa. Universidade do Vale do Taquari UNIVATES. E-mail: delpinojc@yahoo.com.br 


\title{
SCIENTIFIC AND TECHNOLOGICAL LITERACY AS A POSSIBILITY OF CITIZEN TRAINING FROM A HEALTH EDUCATION APPROACH
}

\begin{abstract}
This text presents notes on Scientific and Technological Literacy (ACT) as a possibility for the formation of the citizen and a reflection of an experience of a teacher of the initial years of a school of the state network of Rio Grande do Sul, from an approach of the Health education. In this sense, several analytical opportunities are approached in relation to ACT, starting from the theoretical assumptions of Lorenzetti and Delizoicov (2001), Sasseron and Carvalho (2008 - 2011), Pérez Gómez (2015) and Frizon and Del Pino (2011) among others. We report an activity developed from the refrigerant issue, which was presented at the Works Exhibition of the school involved. It is believed that education should provide the construction of a citizenship to think, make decisions, propose alternatives and able to perceive positive and negative aspects of science and technology. Based on the notes from this text, we can see that there are several possibilities for analysis in relation to ACT in the formation of the citizen, and health is one of them.
\end{abstract}

Keywords: Scientific and Technological Literacy. Formation of the citizen. School. Education and Health.

\section{INTRODUÇÃO}

O presente artigo é resultado dos estudos e discussões ocorridos durante a disciplina de Fundamentos da Alfabetização Científica e Tecnológica do Programa de Pós-Graduação Stricto Sensu em Ensino a nível de mestrado, na Universidade do Vale do Taquari UNIVATES. Este estudo possui como objetivo compartilhar reflexões sobre a vivência de uma professora dos anos iniciais no uso da Alfabetização Científica e Tecnológica (ACT) a partir de uma abordagem da educação em saúde no contexto escolar.

Nessa perspectiva, o mundo contemporâneo exige cidadãos preparados para a ciência e a tecnologia, capazes de compreender os desafios e de tomar decisões favoráveis a ele, e em consonância a isso a saúde torna-se uma área pouco explorada dentro da educação (SANTOS; MORTIMER, 2002). Sendo assim, a escola precisa estar atenta a essa realidade imposta e preparar um sujeito comprometido efetivamente com o ambiente no qual está inserido, instrumentalizando-o para a sociedade.

O conhecimento sobre saúde deve estar presente no currículo escolar como expressão das ferramentas habituais que o cidadão utiliza para compreender a atuar, não para reproduzi-las e consolidá-las, mas para entender a sua lógica. Ainda observando suas limitações e possibilidades à luz do conhecimento mais rigoroso, disciplinado, crítico e criativo (PÉREZ GÓMEZ, 2015). Essas transformações merecem ser refletidas pela escola, visto que implicam diretamente no papel da escola na contemporaneidade e apresentam-se, muitas vezes, como desafios de formar um cidadão reflexivo em sua própria existência. 
Essa abordagem não é recente, a Constituição Federal já previu que a educação fosse direcionada para o preparo da cidadania, e que a saúde estivesse entre os principais direitos e deveres da população (BRASIL,1988). Da mesma forma os Parâmetros Curriculares Nacionais do ensino fundamental indicam como um dos objetivos do mesmo que, "[...] os alunos sejam capazes de compreender a cidadania como participação social e política” (BRASIL, 1998, p. 7).

Conforme Pérez Goméz (2015) as escolas não mudaram significativamente nem sua estrutura, nem seu funcionamento desde a sua constituição como instituição no final do século XIX. Neste sentido, para modificar a situação da educação brasileira, surgiu uma corrente que defende o direcionamento dos currículos das escolas para a Ciência, Tecnologia e Sociedade (CTS), o que significa trabalhar nas salas de aula as "[...] inter-relações entre explicação científica, planejamento tecnológico, solução de problemas, e tomada de decisão sobre temas práticos de importância social" (SANTOS; MORTIMER, 2002, p. 3), neste ponto é que são incluídos a saúde, valores éticos e princípios democráticos. Dessa forma, a escola promoverá o Letramento Científico e Tecnológico (LCT), ou seja, a formação de cidadãos que não só serão capazes de compreender os problemas de saúde, mas políticos, ambientais, sociais, econômicos enfrentados pelo mundo, como também estarão preparados para enfrentá-los, pois terão uma visão crítica e comprometida com a sociedade.

Neste contexto, aborda-se a temática na primeira seção com reflexões sobre a "Alfabetização Científica e Tecnológica", na qual discute-se ACT na formação do cidadão, baseado principalmente nos estudos de Sasseron e Carvalho (2008 - 2011). Em seguida, "Ensino de Ciências e a Alfabetização Científica a partir de uma abordagem da educação em saúde", problematiza-se uma situação vivenciada por uma professora dos anos iniciais, utilizando uma abordagem da educação em saúde a partir dos pressupostos de Lorenzetti e Delizoicov (2001) e também Sasseron e Carvalho (2008 - 2011).

\section{ALFABETIZAÇÃO CIENTÍFICA E TECNOLÓGICA}

Segundo Auler e Delizoicov (2001) a ACT abarca um espectro bastante amplo de significados traduzidos através de expressões como popularização, divulgação científica, entendimento público e democratização da ciência. Em consonância, Sasseron e Carvalho (2011), destacam que o primeiro obstáculo no estudo da ACT se encontra na própria definição do conceito. Ao estudar a literatura estrangeira em relação à didática das ciências, Sasseron e Carvalho (2011, p. 59-60) perceberam uma "[...] variação no uso do termo que defina o ensino de ciências preocupado com a formação cidadã dos alunos para ação e atuação em sociedade". A polissemia desse conceito é decorrente, principalmente, de problemas de tradução, visto que por vezes o conceito é traduzido do inglês "Scientific Literacy", do francês "Alphabéstisation Scientifique" e de espanhol "Alfabetización Científica". 
Entretanto, na literatura brasileira, é possível encontrar alguns fundamentos teóricos que diferenciam os conceitos. Por exemplo, autores que falam em "Letramento Científico", como Mamede e Zimmermann, 2007; Santos e Mortimer, 2001, apoiam seus estudos na área da linguagem, na qual o conceito de alfabetizado e letrado remete a significados distintos. Del Pino e Frizon (2011) defendem que o processo de letramento envolve a preparação do cidadão para ser capaz de ler o mundo fazendo julgamentos críticos e políticos. Assim, o letramento dos cidadãos vai desde compreender os princípios básicos de fenômenos do cotidiano até a capacidade de tomada de decisão em questões específicas da ciência e tecnologia em que estejam diretamente envolvidos, retomando as questões de saúde, sejam decisões pessoais ou de interesse público.

Por sua vez, autores que falam em "Enculturação Científica", como Carvalho e Tinoco, 2006; Mortimer e Machado, 1996 acreditam que é necessário que alunos dominem noções, ideias e conceitos, para participar dessa cultura específica. Partindo de pressupostos realizados por Sasseron e Carvalho (2011, p. 60), em relação a este conceito, os autores que a utilizam acreditam "[...] que o ensino de Ciências pode e deve promover condições para que os alunos, além das culturas religiosa, social e histórica que carregam consigo, possam também fazer parte de uma cultura em que as noções, ideias e conceitos científicos são parte de seu corpus".

Por fim, autores que usam a ideia de "Alfabetização Científica", como Brandi e Gurgel, 2002; Auler e Delizoicov, 2001; Lorenzetti e Delizoicov, 2001; Chassot, 2000, fundamentam suas ideias nos pressupostos da pedagogia crítica freireana, para quem a alfabetização não é somente, a capacidade de reter e memorizar um conjunto de códigos, mas sobretudo a capacidade de conciliar uma leitura de mundo e da palavra, que garantisse ao sujeito uma organização lógica do pensamento e uma visão crítica.

Para Miller (1983) há três dimensões da Alfabetização Científica (AC): o entendimento da natureza da ciência, compreensão de termos e conceitos chaves da ciência e entendimento dos impactos da ciência e suas tecnologias. Por sua vez, Bybee (1995) trabalha com a ideia de AC funcional, conceitual-procedimental e multidimensional. E no mesmo sentido Shamos (1995) instrui a três etapas, a cultural, a funcional e a verdadeira. Percebe-se que em alguns aspectos, as três teorizações convergem. A primeira refere-se ao fato da necessidade de compreendermos o vocabulário científico e bem como alguns conceitos. O segundo aspecto, a qual todos referem-se é o fato de compreender a natureza do conhecimento científico, por fim, convergem ao destacar a necessidade de reconhecer os impactos da ciência e tecnologia em sua vida.

\section{O ENSINO DE CIÊNCIAS E A ALFABETIZAÇÃO CIENTÍFICA A PARTIR DE UMA ABORDAGEM DA EDUCAÇÃO EM SAÚDE}

Segundo Sasseron e Carvalho (2011, p. 72) os sujeitos deveriam compreender ciência de modo a garantir uma melhor formação pessoal e contextualizando ao 
cotidiano do dia-a-dia, assim, a ciência deveria "[...] fornecer subsídios para que os alunos reflitam sobre os problemas que os afligem e busquem soluções e medidas cujas metas visem o futuro sustentável do planeta". Sob este pressuposto buscou-se trabalhar questões referentes à saúde, que em suma não são abordadas no contexto escolar, e ao trabalhar-se na perspectiva do raciocínio crítico faz com que o aluno assimile a aprendizagem como algo em seu contexto.

Mesmo que existam propostas de trabalho que partem do princípio do espírito de investigação e apoiadas em pressupostos construtivistas, o conhecimento trabalhado na escola sobre educação em saúde de modo majoritário é aquele orientado por uma postura de ciência como um conhecimento dogmático. Assim, reforça o estereótipo do conhecimento científico ser decorrente de uma descoberta e não de uma construção. Também, pouco critica-se a ideia cumulativa e linear do desenvolvimento da ciência, tendo-se como base os conteúdos repassados pelo professor em detrimento a bagagem que o aluno carrega consigo.

Sendo o professor o responsável pelo planejamento e concretização das propostas de ensino, é sua responsabilidade propiciar momentos de investigação e argumentação, “[...] muitos docentes parecem ignorar a extrema importância da nova exigência na sua tarefa profissional (PÉREZ GÓMEZ, 2015, p. 28). Nesse mesmo sentido, Sasseron e Carvalho (2011) acreditam que práticas didáticas que almejam promover a AC precisam respeitar três eixos estruturantes.

O primeiro diz respeito à "[...] compreensão básica de termos, conhecimentos e conceitos fundamentais" (SASSERON; CARVALHO, 2011, p. 75). O segundo se preocupa com a "[...] compreensão da natureza das ciências e dos fatores éticos e políticos que circundam sua prática" (SASSERON; CARVALHO, 2011, p. 75). Por fim, o terceiro eixo retoma uma questão já discutida, ou seja, o "[...] entendimento das relações existentes entre ciência, tecnologia, sociedade e meio-ambiente" (SASSERON; CARVALHO, 2011, p. 75).

Em uma experiência docente, a professora envolvida nesta pesquisa relata que foi comunicado que haveria uma Mostra de Trabalhos na escola na qual atua e que todas as turmas deveriam apresentar um trabalho no evento. Sendo assim, a mesma conversou com os seus alunos de quinto ano e fizemos uma atividade de "Explosão de Ideias" sobre qual o assunto que gostariam de trabalhar e sua justificativa. Quase por unanimidade os alunos escolheram o "Refrigerante", e as justificativas foram as mais variadas, conforme seus relatos, identificados com a letra inicial do seu nome:

- Qual os benefícios do refrigerante? A mãe disse que como o refrigerante tem açúcar ele faz bem para o corpo, por causa da glicose (Aluno R.).

- Isso é mentira o que o R. está falando, pois como o refrigerante tem muito açúcar, faz mal para a saúde e enfraquece os ossos (Aluna C.). 
- Eu quero muito estudar sobre o refrigerante, pois tenho diversas curiosidades que quero descobrir, por exemplo, de que é feito, o que de ruim ele causa na saúde e também se é verdade que ele tem muito açúcar (Aluno E.).

- Quero saber as diferenças dos refrigerantes, light, diet e zero. Não entendo porque dizem que tem refrigerante que é zero açúcar, se eu já tomei e é doce (Aluna D.).

- Quero pesquisar se é verdade que o refrigerante é feito com água do rio. Minha prima disse que o não existe fruta de coca, é utilizado carvão com açúcar para fazer o preto (Aluna A.).

O entusiasmo dos alunos foi satisfatório, um assunto significativo tão comum na vida deles e ao mesmo tempo, em alguns aspectos, desconhecido. A AC “[...] preocupase com os conhecimentos científicos, e sua respectiva abordagem, que sendo veiculados nas primeiras séries do ensino fundamental, se constituam num aliado para que o aluno possa ler e compreender o seu universo" (LORENZETTI; DELIZOICOV, 2001, p.7).

Quando a professora relatou para um dos organizadores da Mostra de Trabalhos sobre o que tema a apresentar, a primeira pergunta foi se esse tema estava nos Planos de Estudo daquela turma. Será que os professores devem prender-se somente nos Planos de Estudos das escolas? Acredita-se que um modelo didático adequado para o ensino de ciências em uma perspectiva de AC é necessário que parta-se do contexto do estudante, transformando a realidade em um objeto de análise e reflexão e foi exatamente isso que o professor levantou. Além disso, supõe-se que os modos de investigação oferecem uma melhor compreensão dos estudantes sobre o que é produzir ciências, isto é, percebendo que ciência é resultante de uma construção. Os professores deveriam "[...] propiciar aos alunos a visão de que a ciência, como as outras áreas, é parte de seu mundo e não um conteúdo separado, dissociado da sua realidade" (LORENZETTI; DELIZOICOV, 2001, p.7).

Talvez uma das atividades mais marcantes, foi a pesquisa que os alunos realizaram no laboratório de informática a de quanto de açúcar possuía o refrigerante:

- Aqui nesse site disse que em uma garrafa de $600 \mathrm{~mL}$ de Coca Cola tem 16 colheres de sopa de açúcar. Professora, podemos fazer um teste e colocar em uma garrafa vazia para vermos quanto isso dá? Nossa, 16 colheres de açúcar é muito açúcar, imagina sentar e comer essas 16 colheres, eu não ia conseguir! Isso deve ser muito prejudicial à saúde (Aluno W.).

A professora instigou os alunos a fazer essa representação a partir da primeira representação, fomentando uma série de reflexões sobre o refrigerante e também sobre quantidades matemáticas, como: 
- Se temos 16 colheres de açúcar em uma garrafa de $600 \mathrm{~mL}$, quanto teremos em uma latinha? E em um litrão de 2 L? E um litrão de 3,3 L? (Professora)

Sendo assim, a ciência deve ser produzida em um contexto interdisciplinar, isto

é, que não seja resultado do trabalho de um indivíduos separado. É uma ciência que faça referência a realidade e não a veja apenas como objeto de estudo. Além disso, uma ciência que comporte uma dimensão ética, isto é, que não resultará apenas em uma visão tecnocrática e salvacionista, mas sim que contemple uma dimensão antropológica e sociológica. Esta ciência, que apresenta-se como construção, e não revele apenas suas descobertas, mas sim, demonstre aos sujeitos que o conhecimento científico também possui rascunhos, e estes possam instrumentalizar a boas práticas, como no caso da saúde.

Para Lorenzetti e Delizoicov (2001) a escola sozinha, isolada, não consegue alfabetizar cientificamente seus alunos. É preciso que ela seja sensível ao contexto no qual está inserida, reconhecendo a legitimidade de trabalhar temas/tópicos que sejam de interesse do seu corpo discente. Além disso, é fundamental que ela tenha um projeto político pedagógico orientado para a emancipação do sujeito, e compromissado para a tomada de uma visão crítica do mundo. Se a escola não pode proporcionar todas as informações científicas que os cidadãos necessitam “[...] deverá, ao longo da escolarização, propiciar iniciativas para que os alunos saibam como e onde buscar os conhecimentos que necessitam para a sua vida diária" (LORENZETTI; DELIZOICOV, 2001, p.6).

Por parte do professor acredita-se que ele precisa ter um compromisso ético com os estudantes, reconhecendo que cabe a ele transformar as situações sociais em tópicos de discussão e que dessa forma, haja como facilitador do processo de alfabetização científica. Assim sendo, "[...] ele deve, que por vezes, renunciar o papel de instruir e reconhecer que sua incumbência é estar com o aluno e ser um promotor do diálogo, alguém que instiga o estudante" (SASSERON; CARVALHO, 2011, p. 76).

Acredita-se que a partir disso, a ACT pode ser compreendida como uma ação dialógica entre o conhecimento científico e o conhecimento do sujeito. No diálogo, em uma perspectiva de hermenêutica, compreende uma abertura ao outro, no qual um dos lados não possui uma verdade absoluta, mas no qual ambos agem como um espelho refletindo as necessidade de modificação do próprio pensamento. Complementa-se também que alfabetização é esse ato de abertura para uma leitura de mundo diferente da sua própria, e que por essa diferença abre possibilidade para repensar o modo como o sujeito compreende a sua realidade.

\section{CONSIDERAÇÕES FINAIS}

A ACT, cada vez mais, tem sido postulada enquanto dimensão fundamental numa dinâmica social crescentemente relacionada ao desenvolvimento científico-tecnológico. Contudo, entende-se ser essencial a construção de uma compreensão mais consistente 
sobre a produção e apropriação do conhecimento científico e tecnológico. Percebe-se que nas escolas na maioria das vezes, os alunos não são ensinados como fazer conexões críticas entre os conhecimentos sistematizados pela escola com os assuntos de suas vidas e quando isso acontece, muitas vezes não são "bem vistos" pelos seus colegas de trabalho, assim como o episódio durante o texto.

Verificou-se que a abordagem utilizada por meio da educação em saúde tornou-se eficaz ao passo que instruiu os alunos a buscarem em suas próprias referências situações que pudessem desempenhar conclusões sobre o tema. A atividade tornou-se o início de um grande apanhado reflexivo sobre a saúde no contexto da escola, principalmente em relação ao espaço conferido a ela dentro desta esfera da ACT. O preconceito ainda torna-se perceptível, no entanto a construção de um meio linear de conhecimento torna-se necessário ao contexto relacionado ao ensino em saúde.

Partindo dos apontamentos oriundos desse texto, percebe-se que existem diversas possibilidades de análise em relação à $\mathrm{ACT}$ na formação do cidadão, sendo a saúde uma delas. Acredita-se que o ensino deve proporcionar a construção de uma cidadania para pensar, tomar decisões, propor alternativas e capaz de perceber aspectos positivos e negativos da ciência e tecnologia. Nessa perspectiva, conforme Lorenzetti e Delizoicov (2001) o professor tem um papel de agente transformador. Assim sendo, os educadores deveriam propiciar aos alunos a visão de que a ciência, como as outras áreas, é parte de seu mundo e não um conteúdo separado, dissociado da sua realidade.

\section{REFERÊNCIAS}

AULER, D; DELIZOICOV, D. Alfabetização científico-tecnológica para quê? Ensaio Pesquisa em Educação em Ciências, 2001, v. 3, jun. 122 - 134.

BRASIL. Constituição da República Federativa do Brasil. Brasília, DF: Senado Federal: Centro Gráfico, 1988. Disponível em: <planalto.gov.br/ccivil_03/constituicao/ constituicaocompilado.htm> Acesso em: 26 jan. 2017.

BRASIL. Secretaria de Educação Fundamental. Parâmetros curriculares nacionais: terceiro e quarto ciclos do ensino fundamental (Ciências Naturais). Secretaria de Educação Fundamental - Brasília: MEC/SEF, 1998. Disponível em: <http://portal.mec.gov.br/seb/ arquivos/pdf/ciencias.pdf> Acesso em: 26 jan. 2017.

DEL PINO, J. C.; FRISON, M. D. Química: Um Conhecimento Científico para a Formação do Cidadão. Revista de Educação, Ciências e Matemática. v. 1, n. 1, ago/dez. 2011.

Disponível em: <publicacoes.unigranrio.edu.br/index.php/recm/article/viewFile/1585/769>. Acesso em: 26 jan. 2017.

LORENZETTI, L; DELIZOICOV, D. Alfabetização científica no contexto das séries iniciais, Ensaio - Pesquisa em Educação em Ciências, 2011, v. 3, n. 1, 5 - 12.

PÉREZ GÓMEZ, A. L. Educação na era digital: a escola educativa. Porto Alegre: Penso, 2015. 192p. 
SANTOS, W. P.; MORTIMER, E. F. Uma Análise de Pressupostos Teóricos da Abordagem CTS (Ciência - Tecnologia - Sociedade) no Contexto da Educação Brasileira. Ensaio.

Pesquisa em Educação em Ciências. v. 2, n. 2, dez. 2002.

SASSERON, L. H.; CARVALHO, A. M. P. de. Almejando a Alfabetização Científica no

Ensino Fundamental: a proposição e a procura de indicadores do processo. Investigações em Ensino de Ciências, v. 13, n. 3, p. 333-352, 2008.

Alfabetização Científica: uma revisão bibliográfica. Investigações em Ensino de Ciências, v. 16, n. 1, p. 59-77, 2011. 